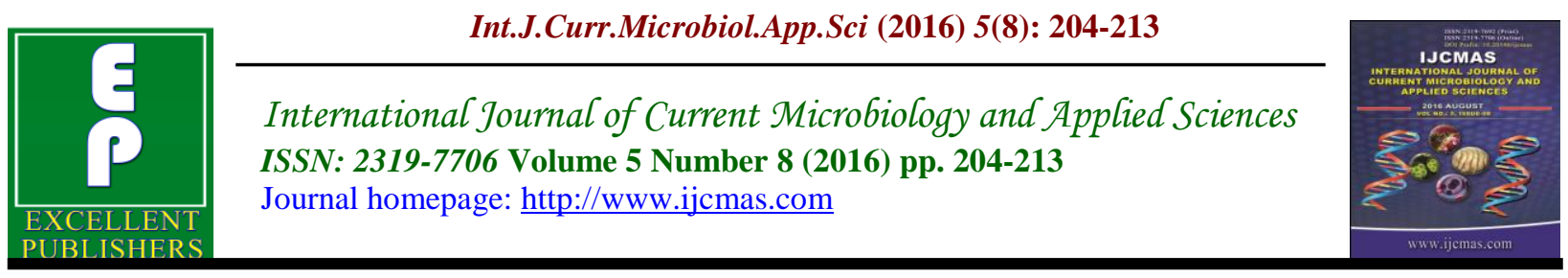

Original Research Article

http://dx.doi.org/10.20546/ijcmas.2016.508.022

\title{
Identification of Prostate Specific Symbiont in Earthworm (Eudrilus eugeniae) and its Role in Reproduction
}

\author{
Divya S. Raj, Bency Rachel, H. Sridhar and S. Umamaheswari* \\ Department of Biotechnology, Manonmaniam Sundaranar University, Tirunelveli- 627012 \\ *Corresponding author
}

\section{A B S T R A C T}

Keywords

Eudrilus eugeniae, 16S rRNA gene sequences, Enterobacter sp. Gene sequence, prostate gland.

\section{Article Info}

Accepted: 12 July 2016 Available Online: 10 August 2016
Earthworms have been found enormously with the presence of symbionts in various organs. The earthworm, Eudrilus eugeniae is harbouring symbionts in the prostate gland. The molecular analysis of 16SrRNA exposed the presence of two bacterial isolates in the prostate gland, one specific for the prostate gland and the other one common harbouring in the clitellum was found out. Gram negative, rod shaped, Catalase negative and Oxidase positive bacterium was identified to be specific for the prostate gland. 16S rRNA gene sequences of the prostate specific isolate indicated its relatedness to the genus Enterobacteriaeceae. Gene sequence assembled and phylogenetic analysis revealed the isolate with $99 \%$ similarity with Enterobacter $s p$. The isolate harboured in the clitellum and prostate indicated its relatedness to Bacillus cereus. Both the bacterial isolates were found to be present in the entire life stages of earthworm. Predominance of the bacterium was found in the stage of cocoon, with least presence at the juvenile stage. Experimental studies explored the importance of prostate specific isolate associated with the fecundity rate.

\section{Introduction}

Earthworms are the major contributors for the structure and dynamics of soil organic matter. These annelids normally weigh around $700-1400 \mathrm{mg}$ after 10 weeks. These tube organisms are becoming increasingly important assay for soil fertility test (Oboh et al., 2007). Studies reveals the stimulation of both the mineralization and the priming effect of soil with the addition and enrichment of several groups especially belonging to the Bacteroidetes phylum by earthworms (Bernard et al., 2012).

Various studies revealed the presence and activity of number of bacteria in the gut of earthworm. Basic methods ranging from various cultural and biochemical characteristics to molecular methods have been employed for the study. The studies have proved the abundance and richness of large portion of prokaryotic community in the earthworm burrows and even in casts which are proved to pass through the gastrointestinal tract of the earthworm unchanged (Furlong et al., 2002; Giere et al., 1987; Hom et al., 2003). Microorganisms and earthworms are enjoying a mutual relationship in which earthworm growth is boosted up by the prokaryotic community and the taxonomic 
addition with enrichment and stimulation of bacterial groups are done by earthworms. This partnership mineralises, humify organic matters and even facilitate chelation of metal ions (Brown, 1995; Drake et al., 2007; Lavelle, 1988; Mieen, 1963). The mutual relationship has even been studied with micro fungi whereby Aspergillus flavus has shown profound amendment in increasing earthworm growth when added with substrates (Pizl et al., 2003). Bright M Giero have given detailed description on the two way integration of microbial symbionts into the reproductive and developmental processes of their hosts ie, through the horizontal and vertical transmission. The horizontally transmitted symbionts are taken up from the environment anew by each host generation rather than inheriting from the parent and vertically transmitted symbionts are most often transferred through the female germ line (Bright et al., 2010).

Earthworm Lumbricidae has been found to harbour Acidovorox in their excretory organ. Specific species are found to harbour through the vertical mode of transmission and other internal and external gut symbiosis occurs through the horizontal transmission where the species can be varied in number and identity. Studies reveal that the symbionts are deposited in the time of development and are colonizing in the egg capsules (Davidson et al., 2010). Even though being a hermaphrodite these tube animals mostly need a mate to reproduce. They have two male openings and two sperm receptacles which can take in sperm from another mate. They have a pair of ovaries that produce eggs. Prostate glands are a pair of large, white, flat, irregular and solid glandular masses lying one on either side of the gut and extending from 16/17th to $20 / 21$ st segment. The prostate gland secretes prostate fluid whose function is still unknown (Gupta, 1999). This work emphasizes the identification of symbiont in the prostate gland.

\section{Materials and Methods}

\section{Collection of sample}

Earthworms, Eudrilus eugeniae collected from the Vermi Biotechnology Laboratory of the Department of Biotechnology, Manonmaniam Sundaranar University, Tirunelveli has been used for the entire study. Gut clearance of the earthworms were performed using $1 \%$ agar medium for 24 hours.

\section{Isolation of Microbes from Prostate Glands}

Earthworm specimens were cleaned with water, given anaesthesia using 7\% ethanol and dissected. The prostate gland was aseptically removed and plated on nutrient agar plates for incubation at $37^{\circ} \mathrm{C}$ for $24 \mathrm{hrs}$. On the other hand aseptically removed prostate gland was surface sterilised by washing with $0.1 \%$ mercuric chloride followed by sterile distilled water for five minutes each. On the other set of experiment, the surface sterilised prostate gland was cut into two halves horizontally and placed on nutrient agar plates, incubated at $37^{\circ} \mathrm{C}$ for $24 \mathrm{hrs}$.

\section{Quantification of Microbes}

Aseptically removed surface sterilised prostate was crushed in $1 \mathrm{ml}$ sterile water. Serial dilution was performed up to 10-6. All the plates were incubated at $37^{\circ} \mathrm{C}$ for 24hrs. In another set of experiment, the prostate was cut into four equal halves viz., Anterior Left and Right, Posterior Left and Right. All the specimens were crushed separately using micro pestle with $1 \mathrm{ml}$ water and serially diluted up to 10-6. The isolated 
single colonies were subjected for further characterization.

\section{Biochemical Characterisation}

The bacterial cultures used during the study were grown in Nutrient Agar at $37^{\circ} \mathrm{C}$ and maintained as $20 \%$ frozen glycerol stocks at $-20^{\circ} \mathrm{C}$. Identification of the isolate was performed according to the Bergey's Manual of Determinative Bacteriology (Williams \& Wilkins, 1994). Morphology of the cultures were identified by Gram's staining and biochemical characteristics viz., Motility, Indole, Methyl Red, Voges Proskauer, Citrate, Catalase, Oxidase and Carbohydrate Fermentation were carried out using standard test methodology.

\section{Molecular Level Characterization- 16SRNA}

DNA was isolated from the selected strain using standard DNA isolation procedure and the sample was subjected for sequencing analysis through a technology service provider at Salem Tamil Nadu, India. Analysis of the nucleotide sequence was performed by using online software of NCBI. Phylogenetic analysis of the strain 1 and 2 was performed. Consensus sequence was aligned for phylogenetic identification with related bacterial strains which was carried out by software generated Phylogenetic Construction Method.

\section{Antibiotic Assay}

Using Disc diffusion method, Antibiotic Susceptibility Assay was carried out for two isolated strains. Antibiotics like Amikacin (30mcg), Ampicillin (25mcg), Cefuroxime (5mcg), Ciprofloxacin $(5 \mathrm{mcg})$, Clindamycin, Erythromycin, Gentamycin (10mcg), Imipenem (10mcg), Kanamycin (30mcg), Methicillin $\quad(5 \mathrm{mcg}), \quad$ Nitrofurintonin (30mcg), Norfloxacin (10mcg), Oxacillin (1mcg), Penicillin (10units), Tetracyline $(30 \mathrm{mcg})$ and Vancomycin $(30 \mathrm{mcg})$.

\section{Identification of LC50 Antibiotic against Earthworm}

Around 50mg of antibiotics viz, Imipenem, Methicillin, Oxacillin, Kanamycin and Erythromycin was dissolved in $1 \mathrm{ml}$ of sterilised distilled water separately. Different concentrations of each antibiotics ranging from $1 \mu 1,2 \mu 1,3 \mu 1,5 \mu 1,10 \mu 1,25 \mu 1$, $50 \mu \mathrm{l}, 75 \mu \mathrm{l}, 100 \mu \mathrm{l}$ were injected into the clitellum region of each set of 5 earthworms. As control same volume of sterile water was injected into the earthworm clitellum. Both the control and test earthworms were incubated in $1 \%$ agar medium. Mortality and morphological changes were noted in every one hour for a period of 24 hours.

\section{Effect of Antibiotics in Earthworm Reproduction}

About50mg of antibiotics viz., Imipenem (10mcg), Methicillin (5mcg), Oxacillin (1mcg), Kanamycin (30mcg) and Erythromycin $(15 \mathrm{mcg})$ were dissolved in $1 \mathrm{ml}$ sterilised distilled water separately. Antibiotics of $2 \mu l$ were injected into the clitellum region of the earthworms. Sterile water served as the control. Control and test earthworms were placed in $50 \mathrm{gm}$ of compost media and their fecundity rate was observed in 30 days.

Quantification of Symbionts in cocoons produced by Kanamycin and Oxacillin injected Earthworm

Antibiotics Kanamycin and Oxacillin were injected into the clitellum region of the earthworm. After 14th day, fresh cocoons collected were surface sterilised and subjected for serial dilution to 10-6 and 
plated on Nutrient Agar medium followed by incubation to enumerate the colonies.

\section{Establishment of Symbionts in the Prostate}

The emergence and establishment of the symbiotic microbiota in the prostate of the earthworm all through its life cycle was evaluated by collection of the various stages of the earthworm's viz., cocoon, juvenile, matured juvenile, pre clitellated and mature earthworm. For a juvenile and matured juvenile the segments from 16 and 20 and for pre clitellated and the matured earthworm their prostate were examined for the presence of the symbiotic microbe using the serial dilution method.

\section{Results and Discussion}

From the gut cleared earthworm, the aseptically removed prostate organs were placed on Nutrient Agar for enumeration of colonies. Absence of bacterial colonies was noticed in the surface sterilised prostate gland samples whereas development of bacterial colonies was observed in the plates where the prostate organ was placed without surface sterilization. But colonies were produced where prostate organ was aseptically removed and also where the organ had been placed as two horizontal halves (Fig 1). The surface sterilization method proved to be efficient in removing the exobiotic bacteria. The experiment in which the prostate was cut and placed indicated the presence of symbiont bacteria in the prostate organ. On quantification of the microbes, two types of colonies were identified and designated as Prostate Specific I and Prostate Specific II (PS I and PS II) (Fig 2 ). However PS I was found to be present both in the clitellum and the head region whereas PS II was absent in both the head and clitellum region (Fig 3).
On observing the localization of the colonies in the prostate gland, the posterior right region harboured higher population of both the PS I and PS II colonies. The anterior right and left and the posterior left region harboured bacterial colonies in the order of $104 \mathrm{CFU} / \mathrm{ml}$ of PS I and $104 \mathrm{CFU} / \mathrm{ml}$ of PS II respectively. The posterior right region harboured the order of $106 \mathrm{CFU} / \mathrm{ml}$ of PS I and PS II. Enumeration results highlighted the predominant harbour of both PS I and PS II (Fig 4) in the posterior right region.

The PS I was confirmed to be Gram positive belonging to the genera Bacillus whereas PS II was identified to be Gram negative of the genera Enterobacter through performance of the preliminary morphological and biochemical identification tests in the lab (Data not shown). Based on the nucleotide homology and phylogenetic analysis, the microbe PS I was detected to be closely related to Bacillus cereus with $99 \%$ identity and $99 \%$ query coverage (data not shown) and PS II detected to be closely related to Enterobacter clocae with $100 \%$ identity and query coverage (Swofford, 2001) (Fig 5).

Results from the antibiotic susceptibility assay towards 16 commercially available antibiotics indicated that both the cultures were resistant to Methicillin, Oxacillin, Ampicillin and Penicillin (Fig 6). Studies pertaining to identification of the LC 50 of antibiotics indicated $2 \mu \mathrm{l}$ of antibiotic to be well below the LC50 values of those antibiotics that could be administrated to the earthworms.

On evaluation of the emergence of these symbionts in various life stages it was found to be abundant in cocoon stage which seemed to reduce through juvenile stage and later found an increase in the succeeding life stages up to adult. A mature worm possessed maximum PS I and PS II while the juveniles 
owned a minimum PS I and PS II (Fig. 7). During the in vitro studies conducted for quantification of symbionts in the prostate gland the sensitive antibiotics such as Kanamycin for PS I rendered a reduction in the PS I colonies to $102 \mathrm{CFU} / \mathrm{ml}$ and Imipenem made a reduction in the number of PS II to 10-1 respectively. The colony count for both the microbes were found to be normal for the Methicillin injected earthworm (Data not shown).The study conducted to find out the importance of PS I and PS II in earthworm reproduction by exposing them to sensitive antibiotics indicated that on injection of the sensitive antibiotic, Kanamycin for PS I, the fecundity rate was observed to be normal on comparison with the control worms. Absence of fecundity rate was observed on administration of the sensitive antibiotics viz., Imipenem and Erythromycin for PS II. Absence of development of cocoons by providing antibiotics sensitive to PS II indicated that the loss of PS II have led to their reproductive efficiency proving the importance of PS II Enterobacter $s p$. in cocoon production (Table 1).

The data obtained from the entire research work clearly describes and provide evidence for the existence of bacterial symbionts in the prostate organ of the earthworm, Eudrilus eugeniae.

Two different bacterial colonies were clearly identified to be present in the prostate organ. Basic microbiological studies and molecular level characterisation confirmed that a single species which is specific for the prostate gland is Enterobacter sp. The other bacterium which was found along with Enterobacter $s p$. was identified as the Bacillus sp. (data not shown) and its presence was confirmed throughout the location of the head and prostate gland whose function is still unknown. 100\% identity was confirmed to the Enterobacter clocae .The fluctuated presence of the Enterobacter $s p$. in the prostate gland with abundance in the cocoon stage with a decline in the juvenile and again abundance at the adult stage clearly explained that this bacteria is entering to cocoon stage through the vertical transmission which later on gets disappeared at the juvenile stage when mating does not takes place and again reappearing in the adult stage to cope up with the motility of sperm and there by cocoon production.

Table.1 Fecundity Rate of Earthworm on injection with various antibiotics

\begin{tabular}{|l|c|c|c|c|c|c|c|c|}
\hline & \multicolumn{4}{|c|}{$14^{\text {th }}$ Day } & \multicolumn{4}{c|}{$28^{\text {th }}$ Day } \\
\hline $\begin{array}{c}\text { Contents injected } \\
\text { into Earthworm } \\
(2 \mu 1)\end{array}$ & \multicolumn{2}{|c|}{ No. of Cocoons } & \multicolumn{2}{|c|}{ No. of Juveniles } & \multicolumn{2}{c|}{ No. of Cocoons } & \multicolumn{2}{c|}{ No. of Juveniles } \\
\cline { 2 - 9 } & I & II & I & II & I & II & I II \\
\hline Sterile water & 4 & 3 & 2 & 3 & 4 & 3 & 3 & 3 \\
\hline Imipenem & 0 & 0 & 0 & 0 & 0 & 1 & 0 & 2 \\
\hline Methicillin & 2 & 3 & 2 & 3 & 3 & 3 & 3 & 2 \\
\hline Kanamycin & 2 & 2 & 3 & 2 & 2 & 3 & 4 & 3 \\
\hline Oxacillin & 4 & 3 & 4 & 3 & 2 & 3 & 3 & 3 \\
\hline Erythromycin & 0 & 0 & 0 & 0 & 1 & 1 & 2 & 1 \\
\hline Control & 4 & 3 & 3 & 5 & 4 & 3 & 3 & 5 \\
\hline
\end{tabular}


Fig.1 Isolation of prostate specific symbionts

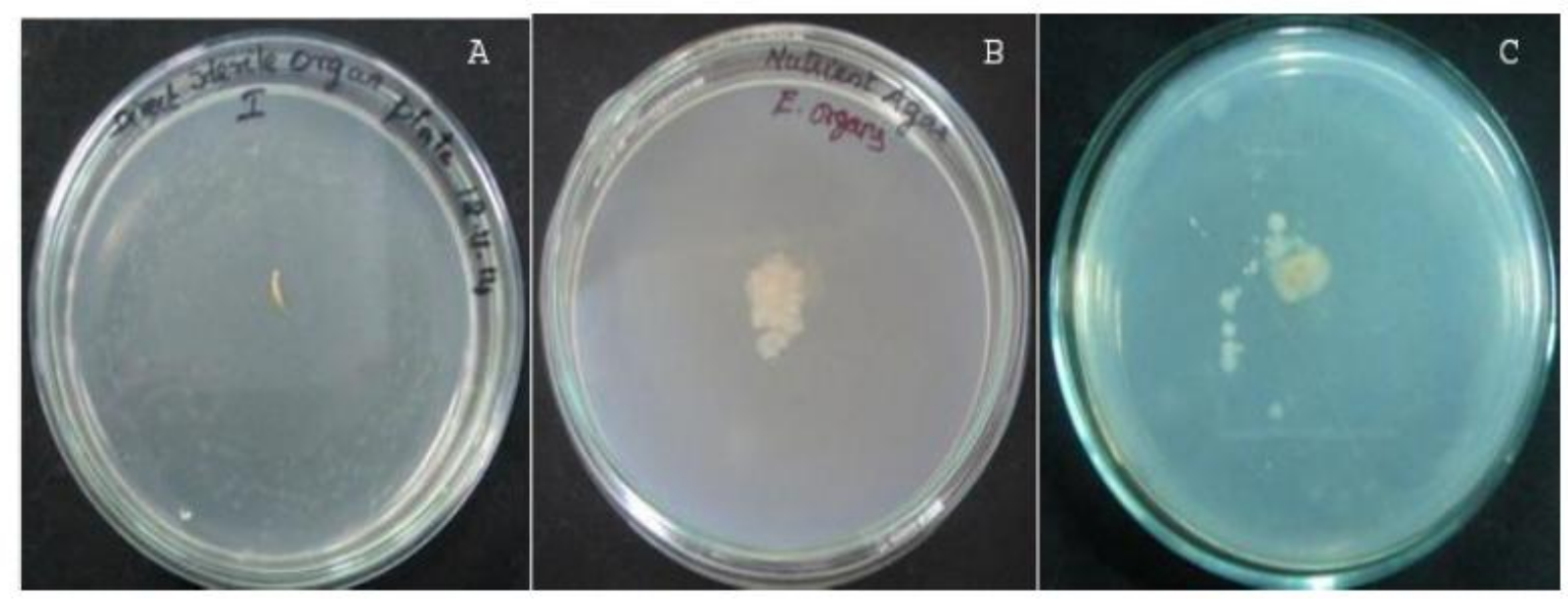

Isolation of culture from Prostate Organ in Nutrient Agar Plates. (A) Surface sterilised Prostate Organ, absence of microbes. (B) Aseptically removed Prostate Organ with bacterial colonies around it. (C) Horizontally cut and plated Prostate organs with colonies around it.

Fig.2 Prostate Specific symbiont - PS I and PS II

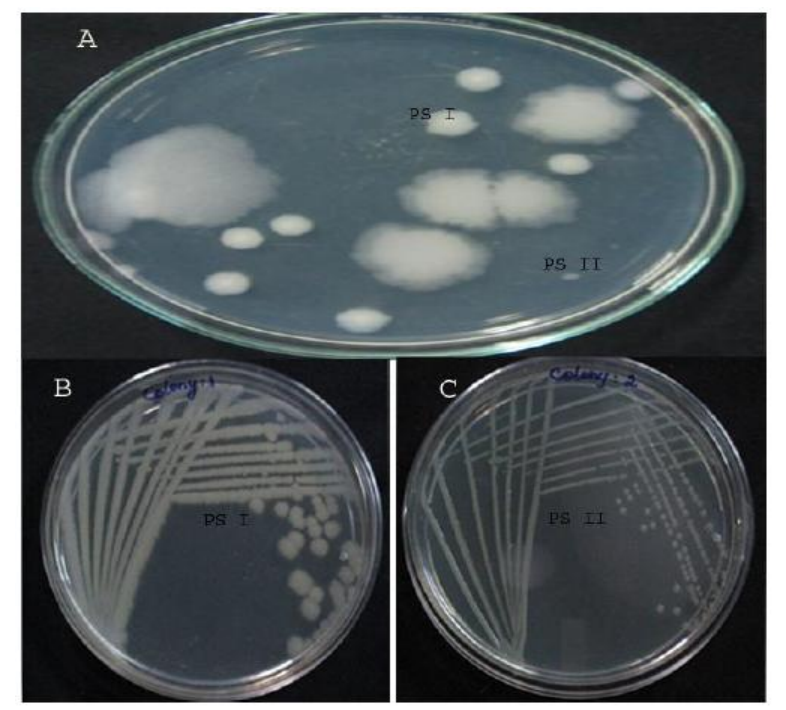

Isolated Prostate Specific Bacterial Colony On Nutrient Agar Plate. (A) Colonies isolated from the Prostate Organ 10-6 dilution. (B) Isolated pure culture of Colony marked on plate as PS I (PS One) (C) Isolated pure culture of Colony marked on plate a as PSII (PS Two) 
Fig.3 Specificity of Prostate specific Symbionts PS II

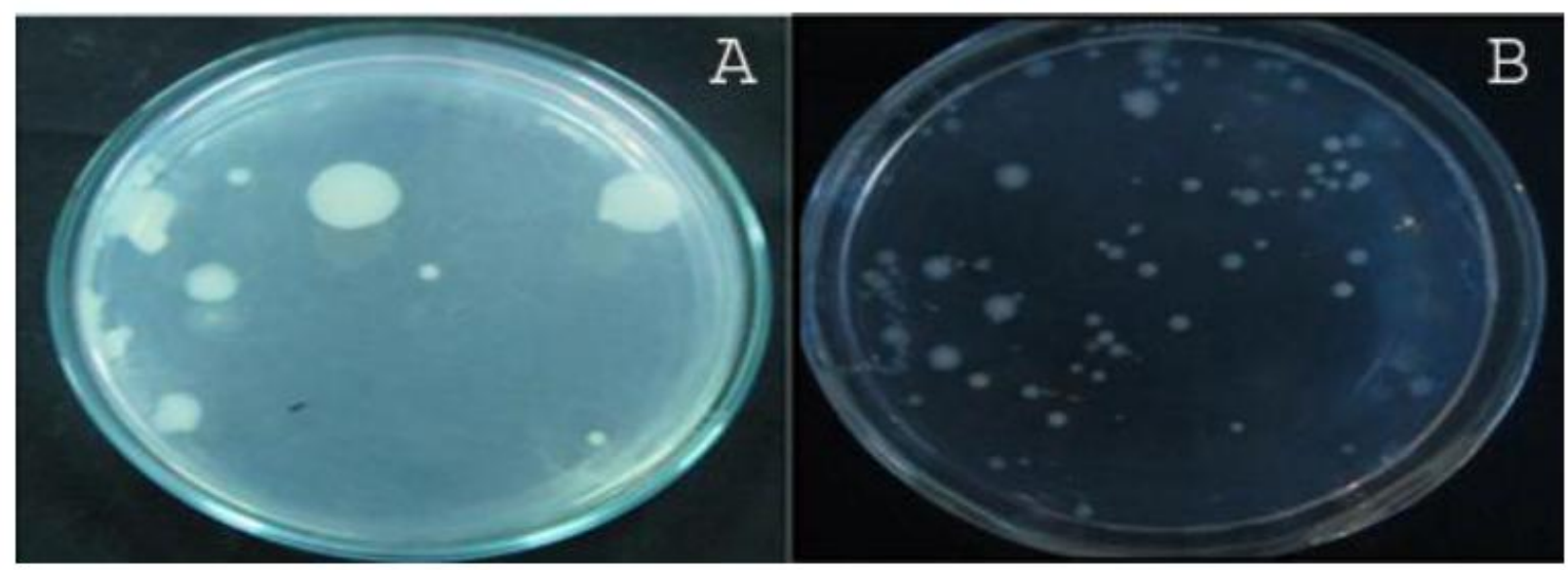

Images of isolation plates. Serially diluted Nutrient plates of head and clitellum regions of earthworm. (A) Clitellum region and (B) Head region. Presence of PS I along with other colonies. PS II colony is absent in head and clitellum region.

Fig.4 Quantification and localization of symbiont microbes in Prostate organ

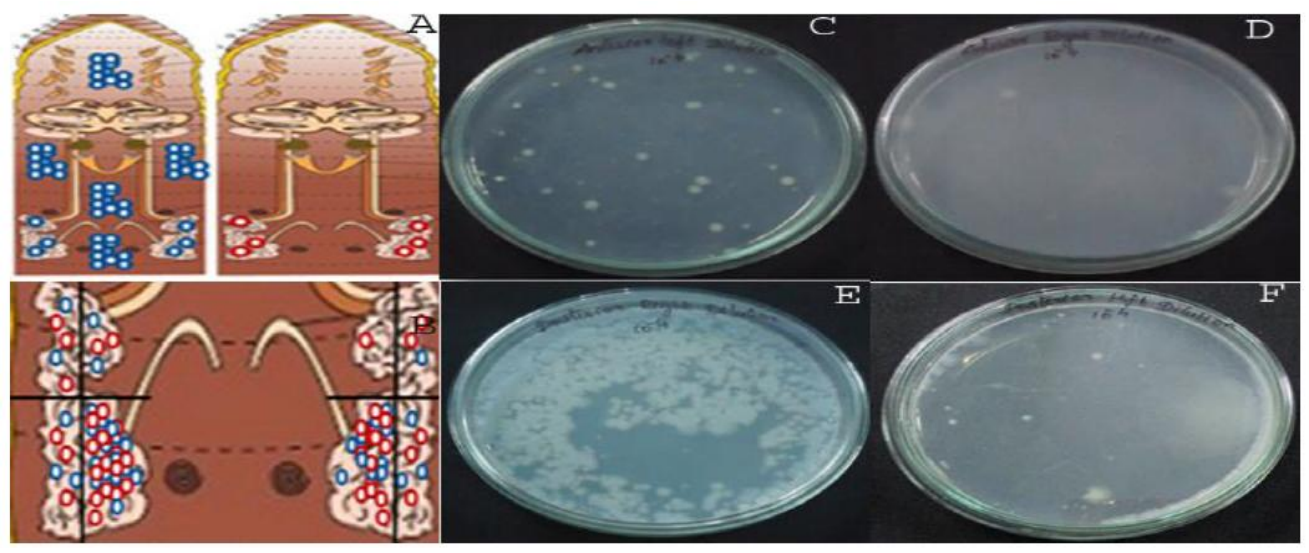

Quantification and localization of symbiont microbes in Prostate organ. (A) Diagrammatic representation showing presence of PS I culture in head and clitellum and absence of PS II in head and clitellum region with specific presence only at prostate gland. (B) Schematic presentation showing Posterior Right region harboring higher population of both PS I and PS II than the other regions. (C)-(F) Culture plate images at 10-4 dilution of symbionts isolated from prostrate regions. (C) Anterior Left (D)Anterior Right (E)Posterior Right (F)Posterior Left. 
Fig.5 Phylogenetic Tree Analysis showing PS II symbiont to be Enterobacter sp.

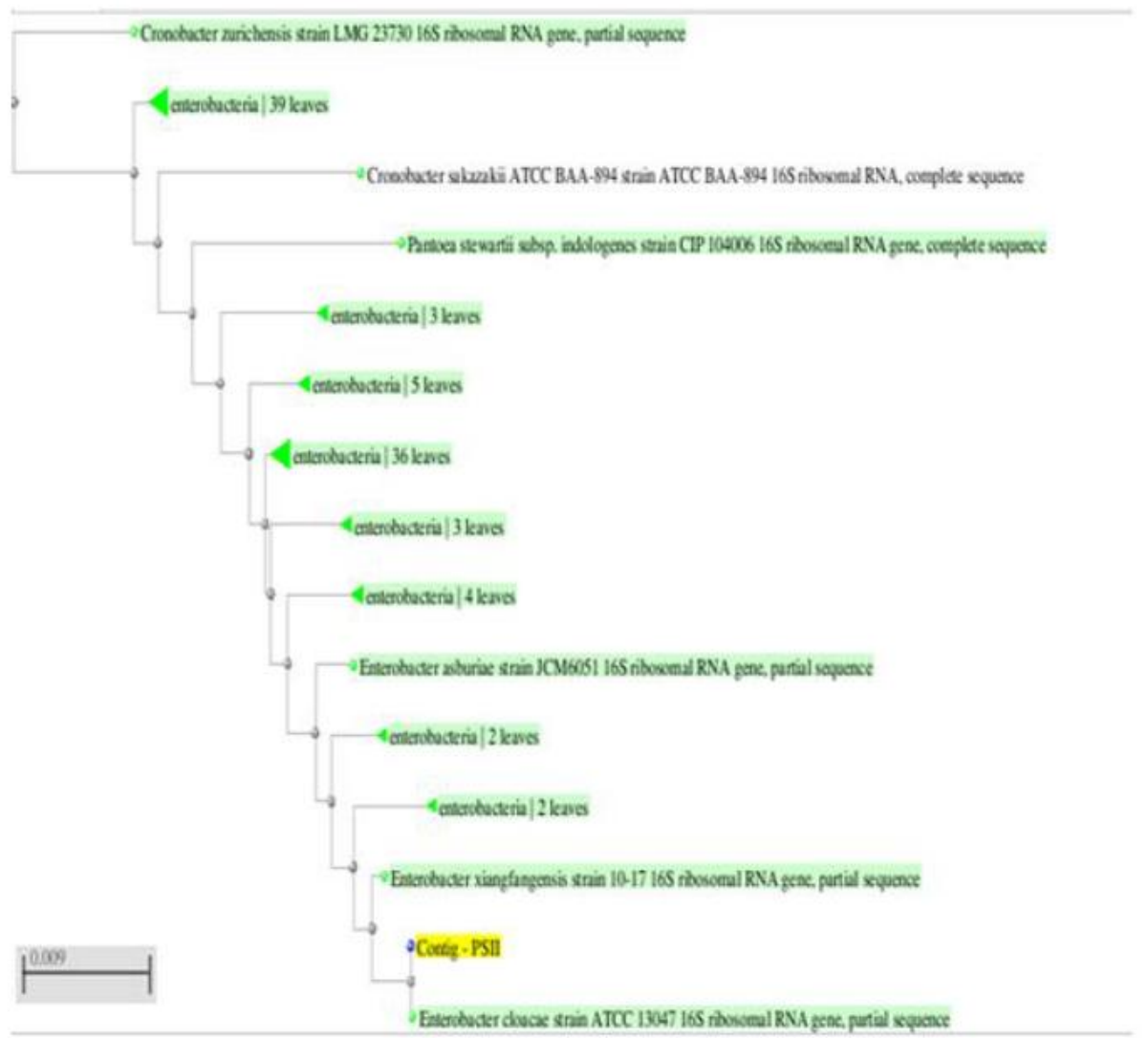

Fig.6 Antibiotic susceptibility test

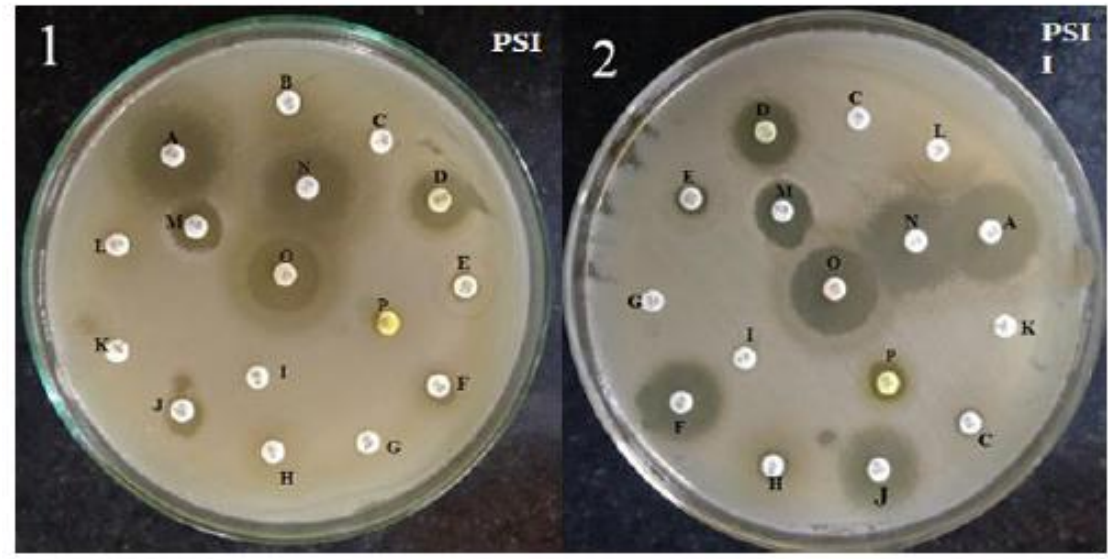

Antibiotic susceptibility testing of PS I Bacillus sp. and PS II Enterobacter sp. against 16 antibiotic discs. A: Norfloxacin, B: Vancomycin, C: Oxacillin, D: Tetracycline, E: Cefuroxime, F: Amikacin, G: Ampicillin, H: Erythromycin, I: Penicillin, J: Gentamycin, K: Methicillin, M: Kanamycin, N: Ciprofloxacin, O: Imipenem, P:Nitrofurintonin. (1) Antibiotic Susceptibility of Bacillus sp. against 16 antibiotic discs and (2) Antibiotic susceptibility of Enterobacter sp. against 16 antibiotic discs. 
Fig.7 Quantification of Symbionts in various life stages of earthworm

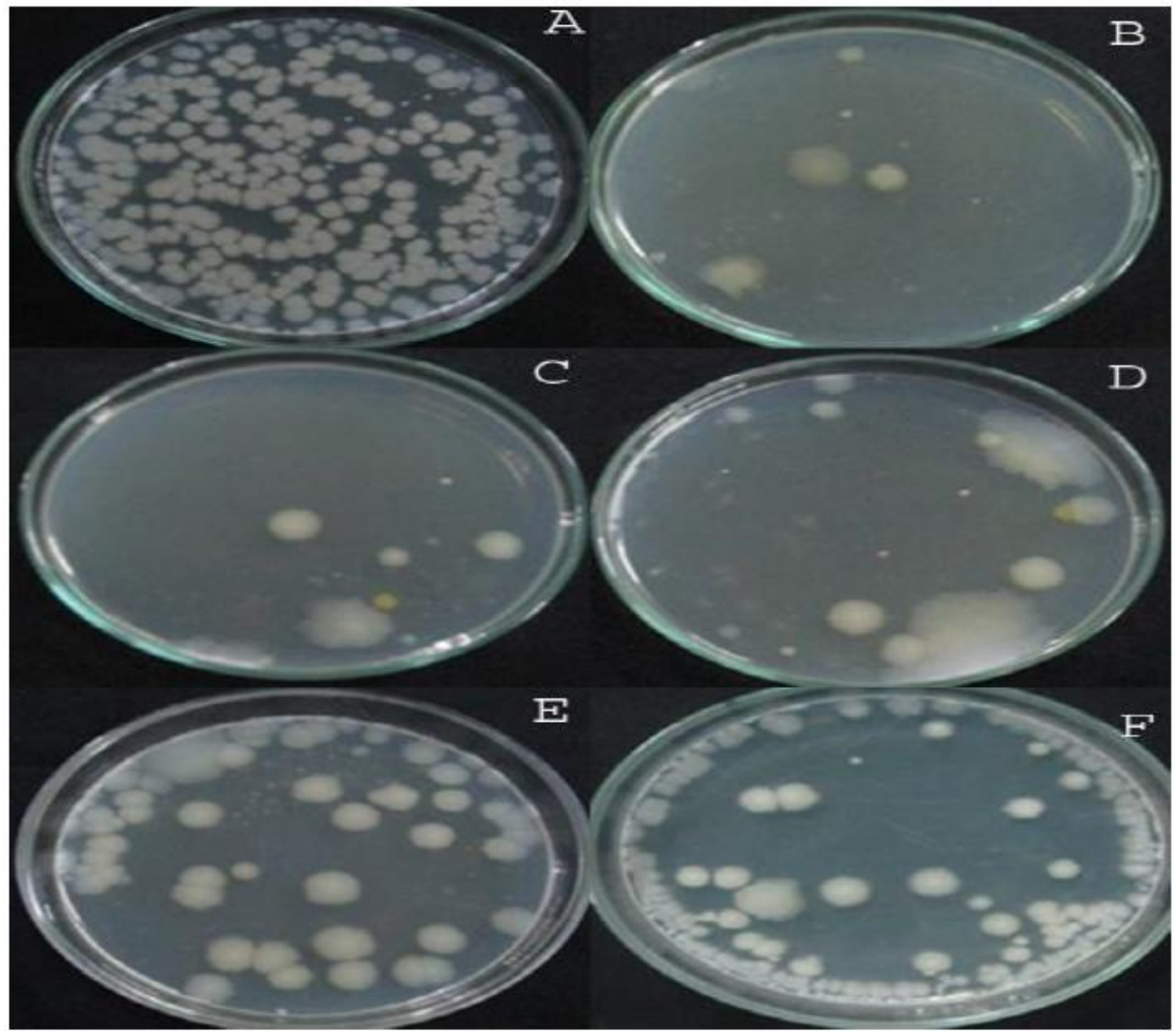

Quantification of Symbionts in various life stages of earthworm from cocoon stage to adult stage.(A)Cocoon 10-2 dilution (B) Juveniles 10-2 dilution I (C) Juveniles 10-2 dilution II, (D) Pre clitellated I 10-4 dilution (E) Pre clitellated II 10-6 dilution (F) Adult earthworm 10-6 dilution.

Position analysis revealed that Enterobacter $s p$. harboures the posterior right region of the prostate gland. The reason for the absence of cocoon production might be due to the absence of Enterobacter $s p$. Which has been identified through the antibiotic sensitivity studies. This finding clearly proves that Enterobacter $s p$. is playing a major role in the reproduction ability of the earthworm, Eudrilus eugeniae and its absence resulted in the loss of reproduction ability.

In conclusion, the earthworm, Eudrilus eugeniae has a pair of prostate organ between the segments 16 to 20 . This prostate organ harbours two types of bacterial colonies. Nucleotide homology analysis revealed the bacteria to be Bacillus cereus and Enterobacter sp. respectively. From the study conducted, Bacillus cereus was found to be present in the head and the clitellum region and Enterobacter sp. was found to be specific for prostate. No hundred percent identity has been found for PS II (Enterobacter species) which revealed the bacterium could be of a new species where further nucleotide studies is mandatory to carry over for the future. The antibiotic susceptibility revealed the presence of symbionts higher in all the stages excepting the juvenile stage and also revealed the importance of PS II (Enterobacter sp) in the fecundity rate. It could be concluded that the 
prostate harbours Enterobacter sp. which in turn is necessary for the reproduction and the absence of the bacterium ends with infertility.

\section{References}

Bernard, L., Chapuis-Lardy, L., Razafimbelo, T., Razafindrakoto, M., Pablo, A.L., Legname, E., Poulain, J., Brüls, T., O'Donohue, M., Brauman, A. 2012. Endogeic earthworms shape bacterial functional communities and affect organic matter mineralization in a tropical soil. The ISME J., 6(1): 213222.

Bright, M., Bulgheresi, S. 2010. A complex journey: transmission of microbial symbionts. Nature Rev. Microbiol., 8(3): 218-230.

Brown, G.G. 1995. How do earthworms affect microfloral and faunal community diversity? In: The Significance and Regulation of Soil Biodiversity. Springer, pp. 247-269.

Davidson, S.K., Stahl, D.A. 2006. Transmission of Nephridial Bacteria of the Earthworm Eisenia fetida. Appl. Environ. Microbiol., 72(1): 769-775.

Drake, H.L., Horn, M.A. 2007. As the worm turns: the earthworm gut as a transient habitat for soil microbial biomes. Annu. Rev. Microbiol., 61: 169-189.

Furlong, M.A., Singleton, D.R., Coleman, D.C, Whitman, W.B. 2002. Molecular and culture-based analyses of prokaryotic communities from an agricultural soil and the burrows and casts of the earthworm Lumbricus rubellus. Appl. Environ. Microbiol., 68(3): 1265-1279.

Giere, O., Langheld, C. 1987. Structural organisation, transfer and biological fate of endosymbiotic bacteria in gutless oligochaetes. Marine Biol., 93(4): 641-650.

Gupta, S.K, Saxena, P.N., Sundararaman, V.1999. An ultrastructural study of the prostate gland of megascolicid earthworm Lampito mauritii (Kinberg). Tissue \& cell, 31(4): 397402.

Horn, M.A, Schramm, A., Drake, H.L. 2003. The Earthworm Gut: an Ideal Habitat for Ingested N(2)O-Producing Microorganisms. Appl. Environ. Microbiol., 69(3): 1662-1669.

Lavelle, P. 1988. Earthworm activities and the soil system. Biol. fertility of soils, 6(3): 237-251.

Mieen, H.B. 1963. Soil protozoa and earthworm nutrition. Soil Sci., 95(6): 407-409.

Oboh, B., Akintobi, D., Ejidereonwu, C. 2007. Morphometric studies in Eudrilus eugeniae populations from different locations in lagos, Nigeria. Nature and Sci., 5(2): 16-21.

Pizl, V., Novakova, A. 2003. Interactions between microfungi and Eisenia andrei (Oligochaeta) during cattle manure vermicomposting: The 7th international symposium on earthworm ecology. Cardiff. Wales. 2002. Pedobiologia, 47(5): 895-899.

Swofford, D.L. 2001. Paup*: Phylogenetic analysis using parsimony (and other methods) 4.0. B5.

\section{How to cite this article:}

Divya S. Raj, Bency Rachel, H. Sridhar and S. Umamaheswari. 2016. Identification of Prostate Specific Symbiont in Earthworm (Eudrilus eugeniae) and its Role in Reproduction. Int.J.Curr.Microbiol.App.Sci. 5(8): 204-213. doi: http://dx.doi.org/10.20546/ijcmas.2016.508.022 